\title{
A fuzzy comprehensive analysis model for the water scarcity evaluation
}

\author{
Xiaozhu Jing \\ School of North China Electric Power University ,Baoding 071000, China;
}

Keywords: Water scarcity, fuzzy comprehensive analysis, physical and economic scarcity

\begin{abstract}
Water scarcity, a problem worldwide, is payed more and more attention to. In this paper, we mainly make an intervention plan taking all the drivers of water scarcity into account. We choose to analyze the water situation of Beijing. In consideration of all the factors caused water scarcity, we use fuzzy comprehensive analysis method to evaluate its water situation. Based on the evaluation system, we analyze the causes in both physical and economic scarcity. Then we give a reasonable evaluation.
\end{abstract}

\section{Introduction}

Fresh water is an essential portion of the production and life, constraining the development in countries. While, the fact is that billions of individuals, approximately a quarter of the world, are going through water scarcity. It was mainly caused by two reasons. The one is that water use has been continuously growing. The other is that environmental and social factors limit water supply. Increasingly, countries are paying attention to alleviating water scarcity, and predict future availability of water. A project should be provided to go into the water scarcity and improve the situation.

To solve the world's water problems, we ought to analyze its supply and demand to measure the ability of providing clean water to meet the needs of its population, and predict the water situation and its impact on the lives of the residents in the future. It is important that why and how water is scarce in the region by the analysis of physical scarcity and economic scarcity. In this paper, we Set up a system to evaluate the water scarcity situation.

\section{Our work}

In this section, we set up a system to give a qualitative evaluation of the water scarcity. Due to the utilization ratio of water resources is closely related to the water scarcity. So we turn on analysis of the utilization ratio of water resources $\left(W_{0}\right)$, using fuzzy comprehensive analysis method. We consider seven evaluation indexes in total, which are ten thousand GDP water consumption $\left(W_{1}\right)$, GDP per capita $\left(W_{2}\right)$, treatment rate of domestic sewage $\left(W_{3}\right)$, annual precipitation $\left(W_{4}\right)$, forest coverage rate $\left(W_{5}\right)$, per capita water resources $\left(W_{6}\right)$, the annual average temperature $\left(W_{7}\right)$. Calculating the degree of association and menmbership, we can get the water scarcity degree (C). Water scarcity degree is divided into 3 levels to evaluate the water situation by the value of $\mathrm{C}$. We apply our system to evaluate the water situation of Beijing, and then discuss why it is water scarcity. 


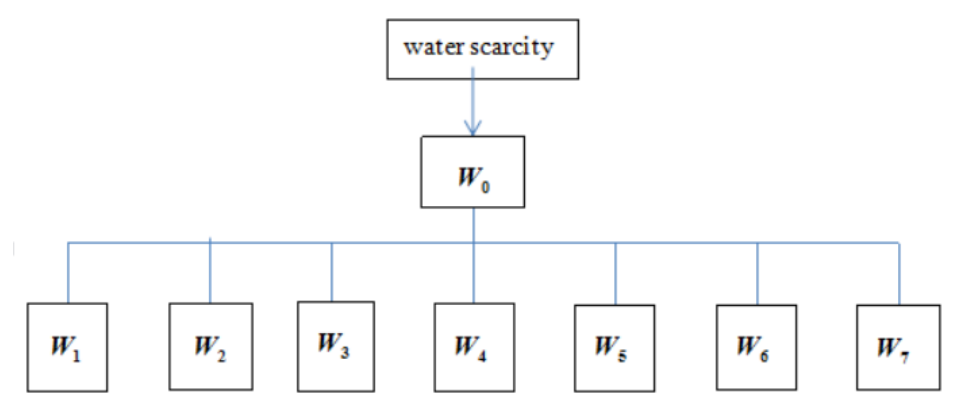

Figure 1. Organization chart of the evaluation indexes

\section{Model III: the evaluation of water scarcity model}

To evaluate the water scarcity, we put forward a equation:

$$
C=A^{T} \times B
$$

\section{- Weight vector (A)}

A is described the association degree of the 7 evaluation indexes and $W_{0}$.

$$
A=\left(\begin{array}{c}
a_{1} \\
a_{2} \\
\cdot \\
\cdot \\
\cdot \\
a_{n}
\end{array}\right), a_{i}=\sum_{j=1}^{7} \frac{r_{i}}{r_{j}}
$$

$r_{i}, r_{j}$ represents vector quantity of the association degree of each evaluation index, $a_{i}$ represents the weight of each evaluation index.

\section{- Degree of menmbership (B)}

$\mathrm{B}$ is described the menmbership degree of the region in our evaluation system. We make the composite analysis of the 7 evaluation indexes worldwide, choosing Australia and Kuwat as our reference standards of the evaluation indexes.

$$
B=\left(\begin{array}{c}
b_{1} \\
b_{2} \\
\cdot \\
\cdot \\
\cdot \\
\mathbf{b}_{n}
\end{array}\right)
$$

According to the value of $\mathrm{C}$, we set three levels, seriousness (level 1), moderateness (level 2) and slightness (level 3).

Table 1. The evaluation criterion of water scarcity

\begin{tabular}{cccc}
\hline Level & level 1 & level 2 & level 3 \\
\hline Range & $c>0.5$ & $0.35<c<0.5$ & $c<0.35$ \\
\hline
\end{tabular}




\section{Application}

\section{Analysis of causes}

We choose Beijing to analyze its degree of water shortage and its reason why its lack of water. According to our modelIII, we use the water scarcity degree $C$ to represent the degree of water shortage in Beijing.

Table 2.shows the real data we find.

Table2. The values of all the evaluation indexes

\begin{tabular}{lllllll}
\hline$W_{1}$ & $W_{2}$ & $W_{3}$ & $W_{4}$ & $W_{5}$ & $W_{6}$ & $W_{7}$ \\
\hline 300 & 1.67 & $90 \%$ & 598 & $42 \%$ & 30 & 10 \\
\hline
\end{tabular}

According to the Degree of membership ,we calculate the value of B:

$$
B=\left(\begin{array}{l}
0.9 \\
0.3 \\
0.1 \\
0.1 \\
0.3 \\
0.9 \\
0.7
\end{array}\right)
$$

So

$$
C=0.47
$$

the degree of water shortage in Beijing is severer than before. Through the degree of membership B, we know ten thousand GDP water consumption $\left(W_{1}\right)$, per capita water resources $\left(W_{6}\right)$ and the annual average temperature $\left(W_{7}\right)$ play an important role in affecting the degree of water shortage.

In conclusion, the main reason why Beijing lacks water can be attributed to three main parts: ten thousand GDP water consumption, per capital water resources and the annual average temperature.

\section{The measures to solve the problem}

Learned from above analysis, we can put forward following advice :

- Increase the amount of water in Beijing and Strengthen the management of water resources. Beijing can divert water from other areas, limit the number of population and improve the utilization of water resources to increase the per capita resources.

- Reduce the energy consumption rate of enterprises and increase investment in science and technology. These measures can improve the situation of water shortage.

- Beijing should call for environmental protection to make the temperature suitable. That can increase the amount of rainfall, which can increase total water resources.

\section{Sensitivity analysis}

$W_{7}$ is an important parameter for the evaluation of water shortage degree. Take $W_{7}$ for example,as is shown in the figure 2 , the rank changes slightly when $W_{7}$ changes, but there are no obviously changes observed on the whole. So we can conclude that $W_{7}$ is an insensitive parameter. 


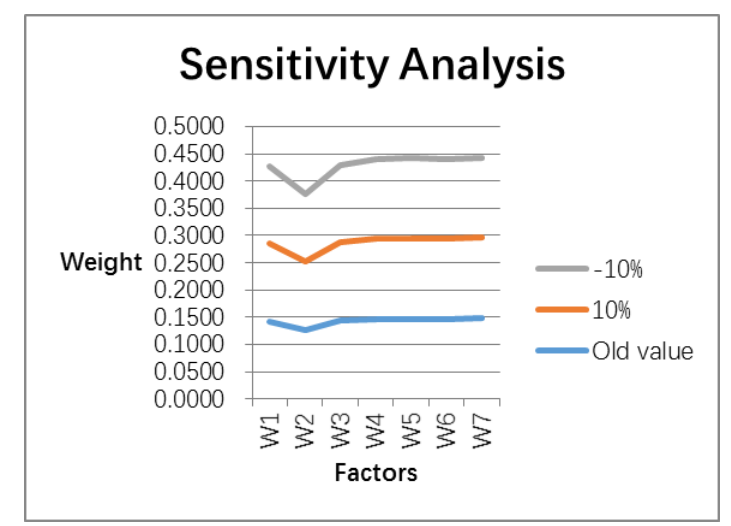

Figure 2. Sensitivity analysis of the evaluation system

\section{References}

[1] G.R. Mettam, L.B. Adams, How to prepare an electronic version of your article, in: B.S. Jones, R.Z. Smith (Eds.), Introduction to the Electronic Age, E-Publishing Inc., New York, 1999, pp. 281-304.

[2] R.J. Ong, J.T. Dawley and P.G. Clem: submitted to Journal of Materials Research (2003)

[3] P.G. Clem, M. Rodriguez, J.A. Voigt and C.S. Ashley, U.S. Patent 6,231,666. (2001)

[4] Information on http://www.weld.labs.gov.cn 